\title{
Compreendendo a natureza das políticas do Estado capitalista*
}

\author{
Reginaldo Souza Santos** \\ Elizabeth Matos Ribeiro*** \\ FÁbio Guedes Gomes**** \\ Leidimar CÂndida dos Santos $* * * * *$ \\ Mônica Matos Ribeiro****** \\ Thiago Chagas Silva Santos $* * * * * * *$ \\ Daniel Andrade CARIBE $* * * * * * * *$ \\ IARA Martins ICÓ SOUTO $* * * * * * * * *$ \\ Cleber Dias da Silva JúniOr ${ }^{* * * * * * * * * *}$
}

Palavras-chave: administração política; Estado; políticas estatais; políticas públicas.

KEY WORDS: political administration; state; state policies; public policies.

\footnotetext{
* Este artigo, recebido em fev. e aceito em ago. 2007, é resultado do trabalho de pesquisa "Políticas públicas baianas nos anos 90: análises e perspectivas", desenvolvido pelos autores, no Núcleo de Pós-Graduação em Administração (NPGA) da Escola de Administração da Universidade Federal da Bahia (EA/UFBA), com financiamento do Conselho Nacional de Desenvolvimento Científico e Tecnológico (CNPq) (mediante bolsa de produtividade científica e apoio financeiro) e da Fundação de Amparo à Pesquisa do Estado da Bahia (Fapesb), no período 2003-05.

** Coordenador da pesquisa, professor titular do Departamento de Finanças e Políticas Públicas e, atualmente, diretor da EA/UFBA. Doutor em economia, com pós-doutorado no Instituto Superior de Economia e Gestão da Universidade Técnica de Lisboa. Endereço: Rua Amazonas, 159, ap. 204 _ Ed. Serra do Nascente - Pituba - CEP 41380-380, Salvador, BA. E-mail: rsouza@ufba.br. $* * *$ Professora pesquisadora do Núcleo de Instituições e Políticas Públicas (NIPP/NPGA) da EA/UFBA. Doutora em ciência política e administração. E-mail: elizabethem@yahoo.com.

$* * * *$ Economista e mestre em economia pela UFPB. Doutorando do NPGA/UFBA. E-mail: fguedes@ufba.br.

$* * * * *$ Pesquisadora do NIPP/NPGA da EA/UFBA. Mestra em ciências contábeis pela Universidade Federal de Mato Grosso. E-mail: leideba@terra.com.br.

$*: * * \cdots *$ Pesquisadora do NIPP/NPGA da EA/UFBA. Mestre em administração pela EA/UFBA. Email:mmrib@yahoo.com.br.

$* * * * * * *$ Mestrando em ciências sociais pelo Programa de Pós-Graduação da Faculdade de Filosofia e Ciências Humanas da UFBA. E-mail: thiagochagas@hotmail.com.
} 
Este artigo tem duas dimensões de análise: uma busca compreender o sentido e a finalidade da política concebida e executada pelo Estado capitalista; a outra investiga a sua natureza, se pública ou estatal. Com isso, tem-se como propósito construir bases conceituais e metodológicas que ajudem a entender um pouco melhor as razões dos sucessos ou fracassos das políticas ditas públicas, particularmente em contextos de países periféricos. Essa construção para o entendimento passa por compreender que o resultado está associado muito mais à forma de gestão da demanda social — administração política — do que à precisão do cálculo previamente estabelecido.

\section{Understanding the nature of capitalist state policies}

This article has two analytical dimensions: the first deals with the meaning and purpose of the policies designed and implemented by the capitalist state; the second investigates their nature, whether public or state. Therefore, the article intends to build a conceptual and methodological framework that will help to better understand about the reasons of the success or failure of the so-called public policies, especially in the context of the peripheral countries. This involves understanding that the outcome is associated much more to the way social demands are managed — political administration — that to the precision of previously established calculations.

No campo das ciências sociais, particularmente quando se trata de abordagem empírica, invariavelmente nos deparamos com afirmações do tipo: dada a crise da economia keynesiana ou, quando não, dada a crise do Estado de bem-estar keynesiano ou a crise fiscal do Estado ou, ainda, dada a globalização...

Porém, muito pouco ou nada se encontra nesses textos, que quase sempre iniciam as suas reflexões com as frases em grifo, alguma preocupação em explicar o que se compreende por "crise da economia keynesiana", "crise fiscal do Estado" ou "mundo globalizado", de um ponto de vista mais sistêmico. Somos todos induzidos a acreditar que essas sentenças são dadas e devemos aceitá-las como fatos consumados. Passa a ser uma espécie de religião, portanto, um dogma, uma ideologia. Temos o dever profissional como produtores do conhecimento de indagar: a forma como o capitalismo se estruturou e foi comandado, pós-crise de 1929-33, até por volta do início da década de 1970,

\footnotetext{
$\because * * * \cdots * \cdots *$ Pesquisador do NIPP/NPGA da EA/UFBA. Mestrando em administração pelo Programa de Pós-Graduação da EA/UFBA. E-mail: dancaribe@yahoo.com.br.

$* * * * * \cdots * * *$ Pesquisadora do NIPP/NPGA da EA/UFBA. Mestranda em administração pelo Programa de Pós-Graduação da EA/UFBA. E-mail: iaraico@yahoo.com.br. ********** Bacharel em administração pela EA/UFBA. E-mail: cleber_dias@yahoo.com.br.
} 
expressou exatamente as proposições de Keynes? ${ }^{1}$ Se a resposta for positiva como não parece ser a mais correta —, então, de qual crise econômica keynesiana está se falando? Há, verdadeiramente, uma crise fiscal do Estado capitalista, particularmente do Estado brasileiro, como foi tão difundida nas décadas de 1980 e 1990 no país?

De um modo geral, uma boa parte da literatura em economia e administração pública toma a crise fiscal como um conceito derivado da categoria crise financeira do sistema capitalista, compreendida pelas dificuldades dos agentes financiarem suas posições devedoras. Entretanto, antes de chegar a esse ponto há uma questão psicológica de importância fundamental: o pessimismo de razões diversas, que toma conta da maioria dos agentes, notadamente daqueles que estão em posição superavitária líquida. As conseqüências são a desvalorização de ativos financeiros e a liquidez de diversas instituições, confirmando e agravando os motivos que geraram o pessimismo inicial. Ainda que esse conceito possa servir de referência inicial para se compreender uma situação de não-liquidez do setor público, é preciso dizer que o Estado possui algumas particularidades que impedem a utilização plena daquele conceito para compreensão da chamada crise fiscal. O fato é que o Estado possui algumas prerrogativas não encontradas nos demais agentes econômicos, a exemplo de poder decidir unilateralmente as políticas fiscal (níveis de arrecadação e a distribuição do esforço de pagar imposto) e monetária (emissão de poder de compra com as vantagens da senhoriagem), além de poder vender títulos da dívida pública tendo a prerrogativa de definir com maior grau de liberdade o preço que deseja receber. Sendo assim, só se poderá falar de crise fiscal do Estado em condições muito especiais, dificilmente encontradas nas economias que estejam em estágios de médio para cima de desenvolvimento das suas estruturas produtivas, particularmente naquelas em que o Estado encontra-se na posição de principal capitalista a comandar os diferentes tipos de atividades capitalistas.

\footnotetext{
${ }^{1}$ Não é uma tarefa intelectual difícil demonstrar que o conteúdo da política econômica e administrativa, construída no período 1929-33, estava para além daquilo que verdadeiramente constituiu a proposta de Keynes. Numa perspectiva de mais longo prazo, talvez fosse mais correto, em verdade, dizer que as proposições contidas em A teoria geral constituíram mais um contraponto ao que estava se conformando como a essência da política anticíclica daquele período de crise do que uma apologia em defesa da intervenção estatal como solução para os males econômicos. Especialmente o capítulo 24 parece ser um mea-culpa de Keynes, talvez não ao que ele diz em A teoria geral, mas ao que é proposto em O fim do laissez-faire, de 1926. Esse tema está sendo estudado pelos autores deste artigo e será publicado em breve.
} 
Desse modo, por mais que a ortodoxia fale em crise fiscal e por mais que isso justifique uma política macroeconômica de ajuste (equilíbrio dos orçamentos de receita e despesa do setor público), esse não tem sido, até aqui, o motivo irradiador de pessimismo entre os agentes econômicos; antes ao contrário, os títulos da dívida pública têm funcionado como instituição seguradora das posições ativas dos agentes, enquanto o banco central, de igual modo, como instituição prestamista de última instância das relações de débito e crédito entre os agentes por meio de empréstimos. Assim sendo, se existe uma crise financeira do Estado, não produz, ou pelo menos não tem produzido, efeitos devastadores a exemplo do que deveria ocorrer com a concepção clássica de crise financeira. O passivo não está deteriorado a ponto de se configurar uma crise sistêmica. Se esta posição que levantamos é uma hipótese de trabalho relevante para revelar o mistério que cerca o debate a respeito da emblemática "crise fiscal", então o que devemos saber é o porquê de tanta insistência em demonstrar a sua existência. ${ }^{2}$

O mesmo parece suceder com o que se convencionou denominar políticas públicas. Quase sempre se tenta compreender por políticas públicas tudo aquilo que for produzido pelo Estado. Em verdade, esse não é o procedimento metodologicamente mais adequado. Se se quer compreender a essência da ação do Estado dentro do contexto das relações sociais de produção e distribuição capitalistas - que são essencialmente descentralizadas e privadas então, tem-se que compreender melhor as seguintes questões: por que o Estado capitalista é obrigado a participar da produção social na extensão que ocorre? Tudo o que o Estado produz tem um caráter verdadeiramente público?

Parece-nos óbvio que responder corretamente a essas indagações nos põe diante de um paradoxo: à medida que invocamos políticas públicas e avocamos para o Estado capitalista a capacidade política e administrativa para realizá-las, mais distantes elas vão ficando dos seus objetivos, ou seja, mais elas vão perdendo abrangência, vão se tornando menos universais e mais particulares.

Para o entendimento desse paradoxo, indagamos: por que se fazem políticas públicas e qual a sua finalidade? Não é difícil entender que na sociedade capitalista as responsabilidades de produzir e distribuir são do mercado, por meio de atos individualizados e egoísticos, mas, ainda assim, uma parcela ponderável da produção social fica sob a égide do Estado. Isso ocorre porque a sociedade, de alguma maneira, manifesta algum grau de insatisfação com os

${ }^{2}$ Sobre este ponto ver Santos (2004). 
atos de produzir e distribuir quando realizados pelo mercado, em particular o ato de distribuir. Ou porque os capitais privados ainda não estão aptos o necessário para desenvolver certas atividades econômicas ou, ainda, simplesmente não os interessa em determinado contexto histórico. Sendo a ação do Estado voltada para atender a uma insatisfação manifestada pela sociedade ou desinteresse ou incapacidade do capital, então, a mesma só tem qualquer sentido se a finalidade última for eliminar a insatisfação manifesta, portanto, a angústia e o sofrimento.

Com isso, é de se esperar que essa ação complementar do Estado no contexto das relações sociais de produção e de distribuição capitalistas possa, ao menos, levar a humanidade à superação do seu esforço cotidiano de produzir a materialidade de que tem necessidade para sobreviver como espécime da natureza. A expectativa em relação a essa superação é reafirmada, inclusive, pelo estágio civilizado alcançado e o alto grau de desenvolvimento da ciência e das técnicas. Entretanto, nada nos faz pensar numa trajetória diferente da que nos tem caracterizado, até aqui, principalmente na etapa capitalista atual: uma capacidade extraordinária de produzir riqueza material associada a outra não menos extraordinária de transformar parte da humanidade em algo abjeto, desprezível e sem possibilidades de acesso a qualquer porção da riqueza produzida. Esse procedimento tem sido tão covardemente aceito como normal que o nosso olhar já parece transformar essa parcela excluída em seres da natureza não mais pertencentes à raça humana!

Desse modo, o projeto para a construção de melhores condições de distribuição da renda e da riqueza deve ser urgentemente iniciado. A sociedade de um modo geral deve ser advertida de que o problema não é o emprego que deixa de ser criado pelo mercado capitalista e sim o problema é o da distribuição da riqueza social. ${ }^{3}$ Quando se fala em formular e implantar uma política

\footnotetext{
${ }^{3}$ Keynes (1984:154-156) nos ajuda compreender melhor esta questão ao dizer:
}

Estamos sendo atingidos por uma nova doença, a respeito da qual alguns leitores ainda podem não ter ouvido, mas sobre a qual ouvirão muito nos próximos anos - ou seja, o desemprego tecnológico. Isso significa um desemprego causado pela descoberta de meios para economizar o emprego do trabalho, a um ritmo maior do que aquele pelo qual conseguimos encontrar novas utilizações para a força de trabalho (...) Trata-se, porém, apenas de uma fase transitória de desajustamento. Afinal, tudo isso significa que a humanidade está resolvendo seu problema econômico. Eu prediria que o padrão de vida nos países em progresso será daqui a cem anos, entre quatro e oito vezes, maior do que o atual. E não seria absurdo considerar a possibilidade de um progresso ainda maior (...) Todavia, acho que não existe país e povo capazes de encarar, sem temor, uma era de lazer e abundância. Isso porque, durante um período demasiado longo, fo- 
social, a sociedade o faz por conta de alguma insatisfação em relação ao mercado que não consegue distribuir adequadamente a riqueza produzida pelo esforço social. E essa distribuição - que deve ser feita, inclusive, pelas políticas sociais do Estado - é uma forma de se iniciar um processo para antecipar a libertação do ser humano da sua obrigatoriedade de lutar, durante toda a sua existência, por uma materialidade que garanta a sobrevivência da espécie. Sinceramente, já evoluímos o suficiente para não acreditar que essa necessidade seja algo imposto pela natureza e da qual não podemos nos livrar. Nada nos indica, portanto, que uns (a grande maioria) nasceram para lutar desesperadamente pela sobrevivência da espécie, enquanto outros (a minoria) já têm essa garantia antecipada pelo direito à propriedade privada e, sobretudo, pelo direito à herança. A instabilidade, a incerteza, o egoísmo e a crueldade são tão determinantes nas relações sociais de produção e distribuição que mesmo aqueles que conseguem alcançar essa materialidade não estão dispensados de continuar lutando por ela, seja porque não conseguem enxergar alternativa para a

mos treinados a lutar e não a gozar. Trata-se de um problema temível para a pessoa comum, sem talentos especiais para se ocupar, principalmente se não estiver mais enraizada na terra, nos hábitos ou nas queridas convenções de uma sociedade tradicional. A julgar pelo comportamento e pelas realizações das classes ricas da atualidade, em qualquer parte do mundo, a perspectiva é muito deprimente! Isso porque tais classes constituem, por assim dizer, nossa vanguarda - que está espionando a terra prometida para o restante de nós, e lá instalando o seu domínio. E porque, segundo me parece, a maioria fracassou desastradamente - os que têm uma renda independente, mas nenhuma associação, dever ou vínculo - em resolver o problema que lhes é proposto (...) Tenho certeza de que, com um pouco mais de experiência, empregaremos a generosidade recém-descoberta da natureza de maneira bem diferente daquela com que os ricos a usam hoje, e delinearemos para nós um plano de vida bem diferente do deles (...) Ainda por muito tempo o velho Adão estará tão forte em nós que todos precisarão fazer algum trabalho para ter satisfação. Faremos mais coisas por nós do que o habitual no caso dos ricos atuais, apenas muito satisfeitos por contar com pequenos deveres, tarefas e rotinas. Mas, além desse ponto, esforçar-nos-emos em espalhar pouca manteiga no pão a fim de tornar o trabalho que ainda restar tão partilhado quanto for possível. Turnos de três horas ou semanas de quinze horas poderão adiar o problema por algum tempo. Isto porque, três horas por dia é o suficiente para satisfazer o velho Adão na maioria de nós!

Os pontos a serem destacados nas argumentações de Keynes são: que para a fatalidade do desemprego tecnológico a saída será uma política de distribuição de renda, com os gastos sociais e a redução da jornada de trabalho; que toda ação para melhorar o desempenho da atividade econômica tem que ter uma finalidade que é a de libertar a humanidade de buscar desesperadamente a materialidade. 
sua existência, seja porque protegendo o futuro dos seus descendentes tem-se a certeza de que ela (a existência) faz sentido da forma como se apresenta. Ou como conclui Keynes (1984:156): “(...) acho que não existe país ou povo capaz de encarar sem temor uma era de lazer e abundância. Isso porque, durante um período demasiado longo, fomos treinados a lutar e não a gozar".

Numa situação bem "menos" egoísta e hedonista relativamente, estão aqueles que, mesmo na labuta diuturnamente, não conseguem sequer alcançar a materialidade indispensável à sobrevivência da espécie humana. A segregação praticada pelo mercado e o alcance limitado das políticas voltadas para a proteção social têm aumentado o infortúnio e encurtado a temporalidade da existência de parcela ampla da raça humana.

Dentro desse processo, o mais grave é que existem aqueles aos quais é negado o direito à consciência da luta pela sobrevivência. Estamos falando daquela parcela da humanidade que, por falta das condições materiais, morre com menos de um ano - e que, portanto, por uma questão biológica ainda não tem consciência da sua existência. ${ }^{4}$ Isso é muito cruel! Então, no estágio em que se encontram a ciência e a técnica, a garantia da materialidade mesmo nos marcos do capitalismo - já é possível para todos, sem maior dificuldade prática, bastando, para tanto, uma única decisão no plano político. Com isso, o homem pode reencontrar-se, dispensando a sua preciosa existência na contemplação das artes da vida, nelas presente o amor! ${ }^{5}$

Se não há uma impossibilidade técnica do capitalismo para realizar essa tarefa, por que, então, esse trabalho permanece inconcluso? Além de outros fatores que possam responder à indagação - a exemplo de um capitalismo tardio ou retardatário, ausência de recursos naturais, baixo estoque de capital, longa permanência como país colônia, baixa escolaridade e con-

\footnotetext{
${ }^{4}$ Numa simplicidade cruel e abominável, as correntes conservadoras e neoliberais buscam solucionar esse problema e, por conseqüência, estados potenciais de pobreza na sociedade, defendendo o controle da natalidade como se praticamente a única causa da pobreza fosse a escolha dos indivíduos em continuar dando prosseguimento à espécie humana, cumprindo a natureza da reprodução da raça. Com esse tipo de idéia absolutamente reacionária, completa-se assim o ciclo do darwinismo social (concorrência individualista, egocêntrica), onde o próprio homem procura conter a sua reprodução. Por um lado, eliminando os "marginais" do sistema com grupos de extermínio, pena de morte e a própria fome e, por outro, limitando a procriação. Assim, dá para deduzir, segundo essa lógica, que lugares como a África e uma boa maioria das favelas brasileiras não deveriam existir, se não tivessem nada de proveitoso para o processo de acumulação de capital, até mesmo o excedente de mão-de-obra que faz diminuir os salários e espalhar o medo da incapacidade da sobrevivência nesses espaços.

${ }^{5}$ Para uma melhor compreensão dessa discussão, ver Santos (2002).
} 
dições políticas apropriadas - , certamente subjaz como fator explicativo uma questão metodológica, em certa medida, ainda pouco explorada no plano teórico e prático.

A constituição do capitalismo é marcada por uma transição bárbara que se inicia com o fim do sonho cristão católico com a contestação da reforma e da contra-reforma e finaliza com o mercantilismo que - apesar da maravilha do novo mundo apontado pela Renascença e pelo Iluminismo - viabiliza o novo modo de produção por meio de uma acumulação primitiva marcada pelos saques, pilhagens e conquistas em (de) continentes e mares. Ou seja, a espoliação é a marca originária e, ao mesmo tempo, permanente do modo de produção capitalista. ${ }^{6} \mathrm{O}$ que dizer da corrupção no setor público e privado, da pirataria, das ações imperiais norte-americanas no Oriente Médio etc.?

O papel da filosofia política, da administração política ${ }^{7}$ e da economia política que nasciam era criar as condições institucionais e sociais que possibilitassem:

- uma identificação mais rápida da natureza e características do novo modo de produção que emergia do feudalismo;

v paralelamente a isso, uma definição das regras e normas (uma nova concepção de gestão) para garantir as bases contratuais da nova sociedade;

v a fundação dos marcos conceituais e metodológicos de uma nova ciência (a economia política) que pudesse compreender as novas relações sociais de produção e mostrasse a sua superioridade em relação ao antigo regime (feudal). Era uma espécie de redescoberta do homem com sua razão.

A perseguição de uma estabilidade nas relações sociais com novas regras de poder foi a preocupação desde os escritos voltados para a compreen-

\footnotetext{
${ }^{6}$ A esse respeito, ver o instigante livro de Harvey (2004).

${ }^{7}$ Não havia uma separação entre esses dois campos do conhecimento — apenas a economia se destacava como um novo campo do conhecimento - , mas, já àquela época, ficava nítido que nos estudos da economia política estava presente a compreensão da administração política formas de gestão das relações sociais de produção e distribuição. O próprio Smith tinha essa clareza ao conceituar o que entendia como economia política - que na nossa opinião está mais próximo do conceito da administração do que mesmo da economia: "A economia política, considerada como um setor da ciência própria de um estadista ou de um legislador, propõe-se a dois objetivos distintos: primeiro, prover uma renda ou manutenção para a população ou, mais adequadamente, dar-lhe a possibilidade de conseguir ela mesma tal renda ou manutenção; segundo, prover o Estado ou a comunidade de uma renda suficiente para os serviços" (Smith, 1985:357).
} 
são das regras de manutenção do poder de Maquiavel e a luta obstinada de Hobbes para construir a paz mediante a institucionalização do Estado; de Rousseau adveio a idéia de fortalecer o pacto com o contrato social estabelecido na sociedade civil até o momento em que Adam Smith se entregou à tarefa de entender as leis que regiam o funcionamento do novo sistema econômico e os caminhos e formas do seu desenvolvimento. A economia política, além desses objetivos, também surgiu como o construto teórico que iria subsidiar as críticas ao Estado absolutista e sua maneira de gerir e regular a sociedade.

O projeto previa que as bases fundamentais do Estado mercantilista deveriam ser substituídas de modo que a sua responsabilidade na produção social se reduzisse ao mínimo, enquanto fosse possível, dando ao mercado essa possibilidade "quase mágica" de ser o soberano das determinações e desejos sociais, bem como o provimento da materialidade. Por outro lado, o projeto contemplava a criação de poderosos instrumentos policiais e jurídicos (um Estado gendarme) que levassem ao cumprimento dos contratos e o respeito às propriedades. Desse modo, a administração política das relações sociais de produção e distribuição dar-se-ia mediante um modelo de gestão descentralizado, em que o mercado e o individualismo (presumido pelo contrato social e guiado pelo hedonismo utilitarista dos indivíduos) seriam responsáveis pela satisfação coletiva.

Nesse sentido, parece claro que o processo histórico de constituição e desenvolvimento do capitalismo adota uma metodologia de conteúdo compreensivo de uma situação de instabilidade que se encaminha para a estabilidade - e essa é toda a lógica compreensiva da Lei dos Mercados de Say que incorpora a situação de pleno emprego como condição normal no capitalismo. Dado que se considera que a estabilidade é um estágio permanente, num período longo, então, tem-se um aumento considerável da renda e da riqueza. Essa dinâmica faz com que, no longo prazo, a curva de renda tenha uma inclinação positiva, enquanto a de despesa ou das necessidades individuais e coletivas seja negativa. Considerando que a distribuição se dá simultaneamente ao ato da produção, logo, à medida que a renda aumenta, aumenta também a situação de bem-estar da sociedade.

Decerto que essa é uma situação idealizada, mas que não ocorre de fato. O capitalismo, em realidade, vive uma permanente instabilidade e a incerteza é sua condição normal, enquanto os instantes de estabilidade passam a ser exceções. Nesse caso, o ciclo longo que permita um nível de distribuição de riqueza de modo a se alcançar uma situação de bem-estar coletivo não se efetiva. Nessas condições, as políticas públicas tornam-se inócuas.

Nesse caso, se se pensa que o objetivo do trabalho social é o bem-estar coletivo, então, tem-se que mudar o sentido da determinação metodológica do 
processo histórico de constituição e evolução do capitalismo. Em vez de se partir da instabilidade $\rightarrow$ estabilidade $\rightarrow$ crescimento econômico $\rightarrow$ desenvolvimento/distribuição $\rightarrow$ bem-estar coletivo, dever-se-ia partir da noção de que para qualquer nível de renda (PQNR) tem-se uma dada política de distribuição/bem-estar coletivo. Caso a renda per capita não seja suficiente para garantir o acesso à materialidade desejável, desencadear-se-ia uma ação no sentido de elevar os índices de desempenho econômico. Nessa condição, a política pública stricto sensu ganha relevância e passa a ter como propósito verdadeiro o bem-estar da humanidade!

Isso não significa que o processo de acumulação seja paralisado automaticamente. Pelo contrário, que a lógica de distribuição da renda e da riqueza seja o ponto inicial para o crescimento econômico e não o contrário. Nesse caso, ganha importância a luta pelo aprofundamento da democracia, onde a população exerça um papel relevante na defesa da desprivatização das políticas públicas, exija e lute pela ocupação de espaços públicos com a finalidade de pressionar no sentido da desmercantilização de certos bens e serviços prioritários que garantam o bem-estar social nas condições adequadas ao contexto histórico do desenvolvimento das forças produtivas. Se isso não ocorrer, e a sociedade aprofundar seus interesses egoísticos e se confinar à sua realidade atomista, o fim da política estará muito próximo.

Em relação à segunda indagação sobre se tudo o que o Estado produz tem um caráter verdadeiramente público pode-se dizer que as políticas desenvolvidas pelo Estado são consideradas como ações públicas pelo senso comum, tendo como referência a utilização de recursos públicos (oriundos da arrecadação, receitas provenientes de organizações e/ou serviços de utilidade pública e empréstimos concedidos, em tese, para fins de bem-estar do todo social). Ou seja, transferência de recursos da população (primordialmente) ao Estado para que ele remaneje esses recursos - de forma universal - para a população, de forma discriminada, para se atingir o desiderato da distribuição. De forma simples, podemos dizer que o poder estatal advém da própria população, da sociedade civil, ${ }^{8}$ que, com suas relações de produção, financia o aparato estatal, colocando em suas mãos a responsabilidade pela provisão das necessidades coletivas e da mediação dos conflitos sociais. Por isso, no plano

\footnotetext{
${ }^{8}$ A sociedade civil, aqui, é tomada como não-homogênea e caracterizada fundamentalmente por diferenciações - particularmente no plano da apropriação da riqueza social - e movida, portanto, por conflitos de interesses entre indivíduos, grupos e, sobretudo, classes. Sendo assim, essa transferência de responsabilidade, mediante o financiamento ao Estado para a provisão das necessidades coletivas, que é feita em meio a muitos conflitos, na maioria das vezes, abertos e violentos.
} 
teórico, diz-se que as políticas do Estado provenientes, em primeira instância, da disposição e financiamento do povo são política pública.

Então, de maneira geral, convencionou-se chamar as políticas desenvolvidas pelo Estado de políticas de natureza pública, sem que o "público" fosse analisado no seu aspecto mais sistêmico. Pois, todas as vezes que nos referimos à expressão "público" vem-nos à mente algo que seja de interesse e/ou de propriedade de toda sociedade, representando os anseios de todos de forma universal. Para isso ser real, teríamos que viver numa sociedade onde os princípios norteadores também fossem coletivos, e não a expressão dos interesses particulares de indivíduos ou grupos sociais. Isto é, a existência do "público" parte do pressuposto de que as vontades e ações individuais são convergentes com a necessidade coletiva, com as demandas universais do todo social - ainda que indivíduos ou grupos que não sejam beneficiários diretamente da política vislumbrem a integração dos resultados dessa ação com outras de seu interesse imediato ou mediato que lhes tragam benefícios diretos. ${ }^{9}$

Segundo Teixeira (2002:2),

"políticas públicas" são diretrizes, princípios norteadores da ação do poder público; regras e procedimentos para as relações entre poder público e sociedade, mediação entre atores da sociedade e do Estado. São esses casos, de políticas explicitadas, sistematizadas ou formuladas em documentos, que orientam ações que normalmente envolvem aplicações de recursos públicos (...) Devem ser consideradas também as não-ações, as omissões, como formas de manifestação de políticas, pois representam opções e orientações dos que ocupam cargos.

A partir dessas observações, cabem algumas questões relevantes: essa "mediação entre atores da sociedade e Estado" considera os interesses de quais classes sociais? O Estado que conhecemos representa os anseios da população ou, pelo menos, da sua maioria? Assim, o poder do Estado pode, então, ser considerado público? As sistematizações das políticas registradas em normas (documentos, leis) foram construídas coletivamente? Por exemplo, o Banco Central é uma instituição realmente pública? Então, por que essa instituição

\footnotetext{
${ }^{9}$ Nem mesmo os economistas neoclássicos mais cuidadosos se arvoram em dizer que toda produção estatal tem um interesse público. Quando do entendimento da natureza dos bens e da determinação de uma tipologia para os bens, são considerados públicos apenas aqueles que estão em condições muito especiais de consumo - ou seja, o consumo de um não implica o deslocamento do consumo de outro e tenham amplas externalidades positivas.
} 
no Brasil não presta praticamente nenhuma declaração, depoimento ou explicações sobre suas decisões perante o Congresso Nacional?

A questão relevante, pois, é a natureza do Estado capitalista. Assim, sabemos que se trata de uma instituição que representa a lógica das relações de produção material de uma sociedade dividida em classes, onde uma classe social detém o poder econômico, e, por extensão, o poder político, sobre as demais. O sistema capitalista realiza-se sobre a premissa da exploração, pois se baseia na acumulação privada de riqueza, onde um grupo tem mais recursos materiais do que o necessário para sua sobrevivência, estabelecendo, assim, um excedente para uns, que só se sustenta pela escassez de outros (grupos sociais das classes oprimidas e mantidas em suas infames posições). A grande maioria dos grupos sociais desprovida de capital, uma vez não tendo possibilidade de adquirir os bens necessários para sua sobrevivência, vende sua força de trabalho (única coisa que lhe resta) para manter-se vivo (a preço estabelecido pela dinâmica da acumulação capitalista), constituindo uma força produtiva controlada e "submissa", mas que é a principal impulsionadora do avanço capitalista, seja como mão-de-obra, seja como consumidora. ${ }^{10}$

Dessa forma, percebemos que o sistema capitalista tem seus valores voltados para a manutenção da supremacia econômica e política de uma determinada classe ou fração de classe social sobre as demais, estando a maioria da população na posição de dominada, pois a acumulação privada tem uma limitação concreta (possível a um pequeno número de pessoas), visto que se baseia na exploração de uma parte da mão-de-obra disponível, enquanto a outra parte é destituída, provisoriamente (talvez permanentemente), do direito ao trabalho, formando aquilo que Marx denominou "exército de reserva", uma das causas da pobreza contemporânea. Então, se o Estado capitalista representa e assegura essa lógica de produção social, não expressa a maioria da população e, sim, o poder dos interesses da classe dominante. Logo, é um Estado de classe, que não pode, na prática, ser con-

\footnotetext{
${ }^{10}$ Um excelente trabalho e pouco conhecido no Brasil é o de Jean-Paul de Gaudemar (1979) que desenvolve, a partir da teoria marxista, o conceito de mobilidade do trabalho, demonstrando, no geral, como o capital responsabiliza-se por produzir o trabalho abstrato e controla também sua própria oferta. Além do mais esse trabalho mostra um fôlego impressionante, quando tece críticas consistentes aos pressupostos da economia política clássica e aos neoclássicos da teoria da localização e derivações, estes últimos buscando compreender a dinâmica dos investimentos industriais e seu deslocamento, bem como as estruturas dos mercados de trabalho. Uma discussão sobre esse texto e sua importância para a compreensão do processo de mudanças no capitalismo periférico e algumas determinações no mundo do trabalho nesses espaços se encontra em Gomes (2006b).
} 
siderado um ente público, defensor dos interesses coletivos e segurador da igualdade social.

Nesse contexto, também se consideram as normas ou leis do Estado como um braço do sistema capitalista, pois elas têm como objetivo assegurar que o processo de acumulação seja considerado "normal" e "natural" e que a sua contestação tenha um caráter imoral, uma vez que essas normas são difundidas e internalizadas pelas instituições "públicas" e privadas.

Assim, elaborar uma política pública significa definir quem decide o quê, quando, com que conseqüências e para quem. São definições relacionadas com a natureza do regime político em que se vive, com o grau de organização da sociedade civil e com a cultura política vigente (Teixeira, 2002:2). Dessa forma, podemos dizer que na conjuntura atual não falamos de políticas públicas, pois elas não são definidas pela coletividade, nem sempre estão voltadas para o bem comum e, normalmente, são realizadas para garantir a expansão capitalista ou amenizar os efeitos negativos da irracionalidade da acumulação privada - o que agrava a sua busca pela legitimidade no encaminhamento de ações que amenizem o grau de insatisfação social.

Poder-se-ia falar legitimamente em políticas públicas se o processo democrático fosse realmente radical, ou seja, se as massas fizessem parte do projeto coletivo de construção da sociedade, e não fossem apenas utilizadas funcionalmente para o processo de produção de riqueza e apropriação privada. Mas como a literatura já vem aprofundando, a democracia não é compatível com o capitalismo, ou seja, mais democracia significa menos arbítrio do capital. ${ }^{11}$

Com isso, se verifica que os gastos estatais não são determinados simplesmente por "leis de mercado", mais do isso, representam os conflitos entre as classes sociais, visto que as ações estatais (ainda que privilegiem a acumulação lucrativa) precisam de uma "aceitação" social, já que os Estados capitalistas são democracias representativas, que, de alguma forma, refletem a intervenção da população, ainda que ela seja moldada pelos valores capitalistas.

O Estado, nessa conjuntura, tem um papel fundamental, pois é por meio dessa instituição, aparentemente aceita por todos, que a dinâmica capitalista ganha corpo. Os gastos governamentais representam um estímulo ao capital, uma vez que funcionam como a locomotiva, seja financiando a empresa privada, em nome do progresso da nação, seja investindo diretamente na produção,

\footnotetext{
${ }^{11}$ Vergopoulos (2005), Boron (2003), Poulantzas (2000), Oliveira e Paoli (1999) e Belluzzo (1993).
} 
seja com políticas sociais que garantam certo poder de compra para população, a fim de que isto mantenha o "ciclo virtuoso" do sistema.

Pelo lado das receitas tributárias, observa-se que a estrutura de classes se expressa nitidamente. No caso do sistema tributário brasileiro isso é emblemático, onde entre $60 \%$ e $70 \%$ do total dos impostos têm origem da cobrança indireta que recai sobremaneira nas classes trabalhadoras e de baixa renda, que não poupam e gastam praticamente toda a renda. Os pobres financiando as políticas de gastos estatais que viabilizam o processo de acumulação e sua segurança social.

Quando O'Connor (1977:19) afirma que o Estado capitalista desempenha duas funções básicas e muitas vezes contraditórias: acumulação e legitimação, isso quer dizer que o Estado deve tentar manter ou criar as condições em que se faça possível uma lucrativa acumulação de capital, enquanto também deve manter ou criar condições de harmonia social.

Essa situação explica o porquê da postura, aparentemente contraditória, do Estado capitalista, suas antinomias. O Estado, mesmo tendo como objetivo assegurar a dinâmica capitalista, não pode agir abertamente a favor de uma classe e em detrimento do resto da sociedade. Em primeiro lugar, porque é a maioria da população que deve definir o poder político do Estado - o que o obriga a atender, de alguma forma, as demandas dessa maioria, num sistema democrático representativo. Em segundo, o Estado precisa justificar sua ação junto aos diversos grupos sociais, uma vez que eles fornecem os recursos (públicos) para o Estado realizar as ações que lhe são cobradas, sobretudo as classes menos abastadas. Por outro lado, se o Estado não defende a acumulação lucrativa, perde seu sentido de controle e coerção social, além de não possuir recursos suficientes para manter seu aparato institucional.

Com isso, a maioria das políticas do Estado tem esse aspecto, digamos complementar, pois ao mesmo tempo em que mantém as condições para a expansão capitalista, trabalha na minimização dos efeitos de sua função de acumulação. A partir daí percebe-se que, mesmo quando as políticas são de cunho social, ou seja, voltadas para a legitimação do aparato estatal, estão a serviço do desenvolvimento capitalista.

As políticas sociais, além de funcionarem como um paliativo, refreando a ação inconveniente da população excluída, em última instância, favorecem financeiramente a classe dominante, porque sua execução está a cargo de empresas privadas, na maioria das vezes, e seus benefícios não são distribuídos de forma justa socialmente. $\mathrm{Na}$ periferia capitalista isso tem se tornado mais grave, porque o Estado tem atuado no sentido da funcionalização da pobreza, com suas políticas compensatórias e assistencialistas, e, por outro lado, servido de prestamista de última instância, pelo seu orçamento, para 
assegurar o processo de acumulação, sobretudo na esfera rentista. Trata-se, portanto, do Estado de exceção, como vem se referindo repetidamente o professor Francisco de Oliveira. ${ }^{12}$

O Brasil, como se percebe, está inserido numa dinâmica capitalista mundial que redefiniu os termos da relação centro-periferia. Nossa estrutura estatal está a serviço do poder econômico (nacional e principalmente transnacional), mas com alguns agravantes. Apesar de ser uma nação independente há dois séculos, o Brasil, assim como todo país periférico, é monitorado pelo poder imperialista de outras nações, resultado de uma economia que se põe dependente. Esse poder tem sido exercido por organismos internacionais (FMI, Banco Mundial, OMC) que ditam as regras de funcionamento e o que deve ser realizado no plano macro em nossas principais instituições.

As políticas estatais brasileiras, quando se referem às despesas sociais, apresentam distorções quanto ao objetivo destinado a essa categoria de gastos estatais, segundo observação feita anteriormente. Em suma, as nossas políticas sociais representam mais um campo direto de acumulação lucrativa de capitais, em boa parte já tendo sido transferida para a realização de empresas privadas, representando a forma mais bem acabada do modelo neoliberal estabelecido na última década.

Os serviços públicos, de interesse da iniciativa privada estão sendo gradativamente transferidos à sua responsabilidade sem nem mesmo uma regulamentação definida, enquanto as áreas de utilidade pública desinteressantes à iniciativa privada estão em total desmantelamento, seja pela destruição da inteligência construída, ao longo da história recente, seja pelo desmoronamento de boa parte da infra-estrutura de setores fundamentais - a exemplo das rodovias, ferrovias, portos, postos de saúde, escolas etc.

A última década foi marcada por um discurso ideológico construído e posto em prática pela corrente neoliberal, que assegura a ineficiência dos serviços públicos gerenciados pelo Estado. Assim, o papel do Estado está restrito à criação das condições para crescimento do capitalismo, com importante peso no campo da desestatização e da constituição de normas legais que garantam o acesso da iniciativa privada como executora dos serviços "públicos", até então estatais. Esse contexto foi criado devido às sucessivas crises do capitalismo, encaradas ideologicamente como crise do Estado, conseqüência direta do redirecionamento do modelo político mundial necessário à expansão do siste-

\footnotetext{
12 Palestra magistral conferida na ocasião da XXI Assembléia Geral do Conselho Latino-Americano de Ciências Sociais, Palácio de Convenções, Havana, Cuba, outubro de 2003. Disponível em: <www.clacso.org >.
} 
ma capitalista e a reintegração da periferia a essa dinâmica remodelada e sob a batuta das altas finanças.

\section{Referências bibliográficas}

BELLUZZO, L. G. Economia, Estado e democracia. Lua Nova, n. 28-29, p. 201-208, 1993.

BORON, A. Estado, capitalismo y democracia em América Latina. In: Coleccion Secretaria Ejecutiva. Buenos Aires: Clacso, 2003. Disponível em: <www.clacso.org/wwwclacso/ espanol/html/libros/estado/estado.html>.

GAUDEMAR, J. P. Movilidad del trabajo y acumulación de capital. Ciudad de México: Ediciones Era, 1979.

GOMES, F. Guedes Conflito social e welfare state: Estado e desenvolvimento social no Brasil. RAP, v. 40, n. 2, p. 201-236, mar./abr. 2006a.

. Mobilidade do trabalho e acumulação do capital: reflexões contemporâneas sobre a produção e reprodução da força de trabalho e controle social. In: ENCONTRO NACIONAL DE ECONOMIA POLÍTICA, 11., Vitória/São Paulo. Anais... Ufes/Sociedade Brasileira de Economia Política, 13-16 jun. 2006b.

HARVEY, D. O novo imperialismo. São Paulo: Loyola, 2004.

KEYNES, J. M. As possibilidades econômicas de nossos netos. In: SZMRECSÁNYI, T. (Org.). Keynes. 2. ed. São Paulo: Ática, 1984.

O'CONNOR, James. USA: a crise fiscal do Estado capitalista. Rio de Janeiro: Paz e Terra, 1977.

OLIVEIRA, F; PAOLI, M. C. (Orgs.). Os sentidos da democracia - políticas do dissenso e hegemonia global. Petrópolis: Vozes, 1999.

POULANTZAS, N. O Estado, o poder, o socialismo. Rio de Janeiro: Graal, 2000.

SANTOS, R. S. Notas metodológicas para a concepção de uma nova política social para o Brasil. RAP, v. 36, n. 6, p. 933-957, nov./dez. 2002.

(Coord.). A controvertida crise fiscal brasileira. Revista Desenbahia, Salvador, v. 1, n. 1, set. 2004 .

et al. Reestruturação produtiva do Estado brasileiro na perspectiva do projeto neoliberal. RAP, v. 38, n. 1, p. 7-32, jan./fev. 2004.

SMITH, A. A riqueza das nações. São Paulo: Nova Cultural, 1985. v. I. (Coleção Os Economistas).

TEIXEIRA, E. C. Movimentos sociais urbanos em Salvador: um mapeamento. In: LUZ, Ana Maria Carvalho (Org.). Quem faz Salvador? Salvador: Universidade Federal da Bahia, 2002.

VERGOPOULOS, K. Globalização: o fim de um ciclo. Rio de Janeiro: Contraponto, 2005. 